\title{
Gunther Gerzso, el esplendor de la muralla
}

María Herrera

\author{
Rita Eder, Gunther Gerzso, el esplendor de la muralla. \\ ERA / CONACUlta, Galería. Colección de Arte Mexicano, 1994.
}

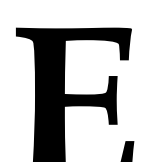

1 libro que comentamos ahora supone un esfuerzo poco común en nuestro medio. Es un intento afortunado de reunir enfoques y textos diversos en torno a la interpretación de la obra de un pintor impor-

\ tante, en su madurez, cuando puede emprenderse ya con cierta perspectiva una valoración de conjunto de su tarea creativa.

El texto principal del volumen es de Rita Eder, responsable también de la selección y edición del libro. En éste encontramos que al cuidado del historiador en la presentación de la información, se une el interés de los análisis conceptuales que nos ofrece, tanto sobre la obra de Gerzso como sobre sus fuentes y el sentido general de su trayectoria. Es preciso señalar el mérito de este empeño por fecundar el trabajo del historiador de arte con la reflexión teórica, no sólo porque es algo que sucede con escasa frecuencia, sino porque los resultados conseguidos tendrían que servir de aliento a esfuerzos semejantes. Por otra parte, el haber incluido también otros textos críticos sobre el pintor -de autores por demás ilustres- me parece una decisión acertada, ya que presenta una visión bastante completa de la recepción crítica de la obra de Gerzso y nos permite comparar y contrastar entre sí esas interpretaciones. Además de que ese diálogo entre sus críticos pone de manifiesto un panorama considerable de discusión sobre teorías e ideas estéticas contemporáneas del más alto nivel, conservando siempre en el trasfondo la obra del pintor como punto de partida y objetivo del análisis.

Desde el punto de vista más bien restringido de la teoría del arte -el que me corresponde por vicio y oficio- más modesto en sus pretensiones de lo que se piensa generalmente, el primer problema a considerar es el de la idea misma de interpretación referida a la pintura. ¿En qué consiste la labor de un crítico de arte, en parte historiador, en parte crítico y filósofo?

Si cuando usamos la palabra "crítica" al hablar de crítica de arte queremos decir "juicio razonado" (como la proponía ya el Romanticismo) tendríamos 
que ser capaces de establecer, al menos, qué clases de razones son válidas para defender una interpretación frente a las opiniones rivales. Es interesante recordar que desde sus inicios, la crítica literaria y de las artes surgió con un tono polémico. No importa con qué frecuencia se sostenga que en materia de preferencias estéticas (o en cuestiones de gusto) no es posible llegar a un acuerdo, puesto que al mismo tiempo, y muchas veces por parte de los mismos sujetos, se afirma con vehemencia que la postura defendida ante una obra o un movimiento artístico es la correcta, o que nuestra interpretación es válida, o al menos, que tiene la pretensión de ser reconocida como tal. No podemos zanjar la cuestión diciendo simplemente que se trata de meras "descripciones", ya que se trata en todo caso de una cierta "traducción" (de las imágenes visuales al discurso) y como tal, supone inevitablemente un proceso de selección, de ordenamiento, de jerarquización (qué se describe, en qué orden, a qué se asigna mayor valor o importancia, etcétera) en otras palabras, se trata de una interpretación.

No obstante, debemos ser cautelosos al hablar de interpretación, en especial cuando nos referimos a la pintura, ya que parecería que no se trata tampoco en sentido estricto de un problema de traducción. No existen códigos que fijen significados estables, ni tenemos acceso a mecanismos que nos permitan comprobar el éxito de nuestra tarea interpretativa: no podemos acudir al ir y venir que ocurre en el uso de las palabras de distintos lenguajes; tampoco tenemos acceso a pruebas pragmáticas, es decir a observar el lenguaje en uso para establecer el rango de sus significaciones posibles. Tenemos entonces que acudir a metáforas: se habla de "leer" un cuadro y no sólo de percibirlo como un fenómeno visual, o de "comprender" el sentido de un poema (más allá, por supuesto, de su significado literal). Con ello, de hecho, estamos suponiendo que la recepción de las artes constituye una forma de "apreciación" que es algo más que un acto de percepción ordinaria, y al mismo tiempo, que no es incompatible con una cierta noción de interpretación. No se trata en modo alguno de limitar la idea de "interpretación" a la identificación de los aspectos figurativos (al "contenido" de la pintura como se le solía llamar en la distinción ya desacreditada de la "forma" y el "contenido" que no es finalmente sino una metáfora visual: la imagen del recipiente, la obra de arte como una botella o un vaso de agua). Más bien, se trata de proponer que la interpretación como un fenómeno universal de la comprensión humana y el arte como una instancia privilegiada de ésta -a la manera en que la entiende Gadamer, uno de los críticos más importantes de la Hermenéutica en nuestros días- supone un movimiento doble: por un lado, un ir hacia el autor o artista, trasladándonos al mundo de sus intenciones y deseos, de sus ideas y emociones, y por otro, un ir de vuelta hacia el horizonte del intérprete, aquel que aprecia y re-significa desde su experiencia e intereses vitales, que juzga y valora apelando no sólo a la razón sino también 
a sus emociones. Esta clase de recepción afectiva es lo que Gadamer llama el "momento de la apropiación" y corresponde a la última fase de la interpretación: aquella que completa el arco comunicativo.

Podría aducirse en contra de esta concepción de la recepción del arte (como una forma peculiar de interpretación) que es válida solamente para un cierto tipo de obras, no sólo para aquellas abiertamente figurativas - otra de las distinciones que tienden a disolverse cuando la miramos de cerca es la de figuración/ abstracción, justamente en casos como el de la obra de Gerzso, una pintura de "figuración ambigua" como la llama Luis Cardoza y Aragón en su texto incluido en este libro. ${ }^{1}$ Una pintura que "no representa pero significa".$-{ }^{2} \mathrm{Al}$ menos, entonces, tendríamos que restringirla a obras que se entienden a si mismas como portadoras de un significado, aún en la forma abstracta de una "idea estética" a la manera en que lo entendían Kant o Schiller, como una imagen sintética de la experiencia de alguna dimensión de la realidad.

No entraremos ahora en la polémica acerca de si el arte ha concluido este ciclo en su auto-comprensión: si efectivamente ha conseguido librarse de toda alusión figurativa o de la clase de recepción afectiva que supone un sujeto como individuo que juzga, valora y aprecia, haciendo uso de sus facultades perceptuales y también de su capacidad de imaginar y recrear el universo interior de otro ser humano tal y como éste aparece expresado en sus obras. Más bien queremos defender la idea de que estos "abandonos" muy bien podrían conducir al vacío de la pérdida de identidad del arte o a la simple confusión o fusión de la producción artística en el mundo de las mercancías. Claramente la obra que nos ocupa no pertenece a esta categoría, es por el contrario, un ejemplo de la defensa de la mirada interior, inteligente y profunda, tanto como serena y capaz de intensidades afectivas. Es, para nuestra fortuna, una obra anterior a la "muerte del sujeto". Y es entonces de éste, y de y en su obra, de quien se ocupan sus críticos en los textos incluidos en el presente libro.

Marta Traba, nos dice, por ejemplo, que las pinturas de Gerzso "jamás podrían ser valoradas en términos puramente formales, plásticos", y para Rita Eder, tanto como para Dore Ashton, los "paisajes de la conciencia" de Gerzso (como los llama John Golding) siempre implican la apertura, más allá o detrás de ellos, de otros espacios inexplorados e impenetrables. ${ }^{3}$ Pero la interpretación sobre el sentido de esa realidad interior en la pintura de Gerzso sigue cursos distintos entre los críticos aquí representados: mientras que para algu-

1 "Gunther Gerzso", p. 169. (Todas las referencias corresponden al libro reseñado).

${ }^{2}$ Como dice Octavio Paz citando al mismo Cardoza y Aragón en: "Gerzso: La Centella Glacial", p. 170.

${ }^{3}$ En los textos incluidos en el presente volumen: Marta Traba, "Gunther Gerzso", pp. 170-175. John Golding, "Gunther Gerzso. Paisaje de la Conciencia”, pp. 175-179. Dore Ashton, "La Pintura de Gunther Gerzso", pp. 180-182. 
nos el peso recae en la continuidad del espíritu Surrealista -para Octavio Paz el tránsito de Gerzso de la figuración a la abstracción no supone una ruptura con el Surrealismo que conserva más como un "sistema de alusiones" que de formas- o para Marta Traba, quien ve esta continuidad en el uso de técnicas Surrealistas como la yuxtaposición de elementos insólitos (más que en la referencia a la magia o al inconsciente freudiano) así como en la conservación de un cierto "punto de vista sobre la existencia". Para otros, como Luis Cardoza y Aragón, las distintas etapas de la pintura de Gerzso supondrían, en especial en el caso del Surrealismo, una suerte de ruptura o discontinuidad. Habría, en fin, otras coincidencias y discrepancias: en algunos casos, se hace jugar a la influencia del Cubismo el papel protagónico en el desarrollo del lenguaje pictórico de Gerzso, mientras que en otros se sugieren alternativas interesantes, como la de Marta Traba, quien atribuye a su trabajo como escenógrafo el haber adquirido una especial maestría en la "racionalización de la ilusión" que le habría permitido ver a sus "paisajes" no sólo como "campos" sino como "muros" y "telones".

Algo que estos textos tienen en común, sin embargo, a pesar de sus discrepancias importantes, es el entenderse como esa clase de interpretaciones a las que antes aludíamos. Se trata de visiones o "lecturas" de la obra en su conjunto y de la trama de sus relaciones internas que entretejen una historia, que construyen una red de sentidos que van de la vida a la pintura -y que no sólo surgen de la propia pintura- para crear en ella un mundo propio, un lenguaje plástico altamente original.

De acuerdo con lo dicho, la historia de la reflexión estética podría ser caracterizada, al menos en parte, como una crónica de modos de interpretar más o menos afines o adecuados a sus objetos. Si las artes visuales son maneras de ver el mundo cristalizadas en formas sensibles, las "lecturas" críticas de las obras son intentos de esclarecimiento que suponen una difícil traducción entre lenguajes heterogéneos. Por un lado, carecemos de reglas o criterios estables que nos sirvan de guía en esta tarea, y por otro, las convenciones que crean los discursos de la crítica y la historia de las artes poseen un alcance limitado: tanto por su apego a movimientos o modas en el mundo del arte - un caso típico es el de los formalismos estéticos- como por su escaso poder explicativo ante obras que se resisten a ingresar sin mayores problemas al catálogo de las codificaciones establecidas. Esto supone indudablemente una limitación: cuando una teoría estética depende excesivamente de las prescripciones y prohibiciones de un estilo o movimiento artístico se ve afectada por una peculiar ceguera: una incapacidad de comprender obras que propongan nuevas maneras de construir sentidos.

De ello, sin embargo, derivamos también una ventaja: el que podamos defender con buenas razones que algunas interpretaciones o "lecturas" de las obras de arte son mejores que otras. Tendríamos que concluir que el éxito o la 
buena fortuna de una interpretación frente a otras tiene que ver con su plausibilidad en el contexto de la totalidad de la obra del autor, con su posible constatación con las opiniones que el artista tenga o haya tenido de la misma, y por último con ese difícil acuerdo (ya que no creemos más en el "sensus communis" de Kant) entre las opiniones autorizadas. Como caso extremo, no obstante, cabe la feliz paradoja en las interpretaciones sobre el arte de poder acomodar "lecturas" dispares de una misma obra, no sólo porque atiendan a aspectos distintos de la misma o hayan sido emprendidas desde perspectivas distintas (la metáfora visual nos sugiere un relativismo de la visión permisible) sino porque el momento de la "apropiación", es decir, la recepción desde una visión particular, subjetiva, permite licencias inadmisibles en otros campos. En el arte es posible incluso discrepar con el autor acerca de su propia obra. Pero más allá de estos posibles juegos interpretativos, aún en esos casos, tendríamos que intentar ofrecer razones para defender nuestra postura o particular apreciación de alguna obra.

Regresamos así a la idea de que pueden existir lenguajes críticos más cercanos a sus objetos de reflexión. La prueba de su eficacia, por otra parte, tendría que ponerse de manifiesto en aquello que se pide de toda buena crítica: su ayudarnos a descubrir aspectos nuevos de las obras u ofrecer modos de lectura más comprensivos, más abarcantes y coherentes de la obra en su conjunto. Esta es una de las virtudes del libro de Rita Eder. Su interpretación de la obra de Gerzso no sigue pasivamente las prescripciones del discurso crítico predominante, entre otras razones porque, como lo observa John Golding en su texto incluido en este mismo volumen, su obra se resiste a los análisis y clasificaciones establecidas. Más bien, la "lectura” que nos ofrece Rita Eder se gestó lentamente en el tiempo que duraron las entrevistas que hizo al pintor, en el que las interpretaciones previas se fueron modificando al prestar un oído atento no sólo a las opiniones del pintor sobre sus obras y sobre la pintura en general, sino también al atender sus gestos, observar sus actitudes, y configurar así una imagen más compleja de las relaciones entre su forma de ser y de vivir y su quehacer artístico.

Es interesante también contrastar esta visión con las opiniones críticas sobre la obra de Gerzso reunidas en el mismo volumen. De ese modo podemos observar que uno de los aspectos que distinguen al trabajo de Rita Eder es el de no limitarse a la descripción y análisis de las obras. Además de establecer ideas generales acerca de la trayectoria y evolución del pintor le interesa preguntarse -en una especie de "hermenéutica de la pintura"- sobre el ejercicio de ésta como tarea cotidiana, buscando en los modos del hacer una guía para desentrañar el sentido de lo hecho, en un intento por ver a la obra como un conocimiento práctico palpable de los límites y posibilidades del oficio.

En el caso de la pintura de Gerzso, se trata de investigar la relación del artista 
consigo mismo y con el mundo en el uso de sus materiales, en las maneras a la vez puntuales y constantes en las que éstos registran su historia como medios expresivos: cómo puede una forma - un color, una línea- "representar" una emoción. Aquí, la insistencia del pintor en el contenido emocional de su pintura encuentra eco en la lectura que Rita Eder ofrece de ella: la estética de Gerzso se nos ofrece como una estética de la representación expresiva. O mejor dicho, como un jugar con las nociones de representación. Representar no sólo quiere decir en su obra establecer relaciones convencionales de significado sino "tomar el lugar de" algo: una línea que se transforma en rasgadura, en alusión al sexo, o en herida, o planos de color que representan niveles o "capas" del continuo de la experiencia; o formas arquitectónicas que se convierten en autorretratos, espacios construidos que son habitados y que sirven a la vez de resguardo a la intrusión de los otros. La tarea del crítico -y del observador atento de su obra- se transforma en descubrir cómo a partir de estas asociaciones que encuentran su sentido y justificación en el uso que hace de ellas el artista, se genera un sentido, una secuencia y un orden; cómo a partir de ellas se construye un lenguaje propio, una poética, que en palabras de Baumgarten, sería la conjunción de la invención y la fantasía. En la repetición de los motivos pictóricos, en las maneras de ver y hacer de su oficio, en esa mirada convertida en uso técnico de los materiales (en ese aprender a "tocar con la mirada" como diría Cézanne) logra el pintor establecer sus "señas de identidad" y asienta las claves para la apreciación (y no sólo para la interpretación) de su obra.

Así, al alejarse del dogma del abstraccionismo y de su prohibición de la representación, la pintura de Gerzso se abre al mismo tiempo a otras manifestaciones plásticas cultural y temporalmente remotas, como el arte prehispánico. Lo que es interesante señalar en este acercamiento, observado también con claridad por Octavio Paz, es que se trata de un encuentro de sensibilidades. Podríamos decir que no se reduce a una mirada completamente externa, a una apropiación de aspectos formales de algo que se presenta como lo absolutamente "otro". Más bien parecería, por ejemplo, que el acudir de Gerzso no sólo a los aspectos visuales sino a la poesía de estas culturas (al acompañar de textos mexicanos antiguos su serie del "Árbol Florido") buscara confirmar su afinidad con las dimensiones universales de aquellas culturas.

Finalmente, podemos ya sólo mencionar algunos de los temas que se intercalan en la discusión en torno a la obra de Gerzso: tales como el del valor del arte como conocimiento, o los problemas del concepto de representación pictórica, o el sentido y tarea de la reflexión estética en nuestros días. Temas que atestiguan tanto la profundidad de la reflexión de los autores aquí reunidos como el valor ejemplar de la obra que motivó estas reflexiones. 
